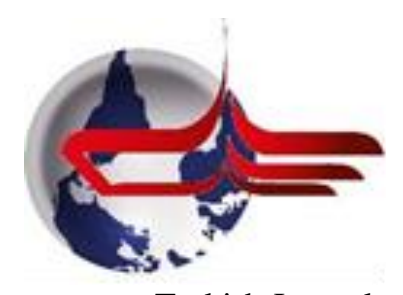

Turkish Journal of Educational Studies, 5 (3) Ekim 2018

Research Article / Araştırma Makalesi

Article Info/Makale Bilgisi

Received/Geliş: Ağustos 2018 Accepted/Kabul: Ekim 2018

\title{
Matematik Dersi Öğretim Programının (Ortaokul 5-8. Sınıflar) Matematiksel Model Kullanımı Bağlamında İncelenmesi*
}

\section{Investigation of the Mathematics Curriculum (Middle School $5^{\text {th }}-8^{\text {th }}$ Grades) in the Context of the Use of Mathematical Models}

\author{
Fatma ERDOĞAN ${ }^{* *} \quad$ Cihan ELMAS***
}

\section{$\ddot{O} z$}

Matematik Dersi Öğretim Programı'nda öğrencilerin kişisel, sosyal, akademik ve iş hayatlarında ihtiyaç duyacakları yetkinliklerden birinin matematiksel yetkinlik olduğu belirtilmektedir. Matematiksel yetkinlik, düşünme ve sunmanın (formüller, modeller, kurgular, grafikler ve tablolar) matematiksel modlarını farklı derecelerde kullanma becerisini içermektedir. Bu doğrultuda, araştırmada Matematik Dersi Öğretim Programı'nın (Ortaokul 5-8. sınıflar) matematiksel model kullanımı bağlamında incelenmesi amaçlanmıştır. Araştırmada nitel araştırma yöntemlerinden doküman analizi kullanılmıştır. Araştırmanın verileri, 2018 yılında Talim Terbiye Kurulunca yayımlanan Matematik Dersi Öğretim Programı’nın analizinden elde edilmiştir. Veri analizi sürecinde programda yer alan öğrenme alanları, kazanımlar ve kazanımlara yönelik açıklamalar matematiksel model kullanımı bakımından incelenmiştir. Araştırma bulgularına göre, Matematik Dersi Öğretim Programı'nın hem kazanımlarında hem de kazanımlara yönelik açıklamalarda matematiksel model kullanımına yeterli seviyede yer verilmediği belirlenmiştir. Kazanımlardan ziyade, kazanımlara yönelik açıklamalarda matematiksel model kullanımına daha çok yer verildiği görülmüştür. Matematiksel model kullanımının en çok sekizinci, en az ise altıncı ve yedinci sınıf kazanımlarında yer aldığı saptanmıştır. Ayrıca, beşinci, yedinci ve sekizinci sınıf kazanımlarında matematiksel model kullanımının en çok veri işleme öğrenme alanında, altıncı sınıf kazanımlarında ise geometri ve ölçme öğrenme alanında yer aldığı belirlenmiştir.

Anahtar kelimeler: Matematik Dersi Öğretim Programı, model, matematiksel model, matematik eğitimi

\footnotetext{
*Bu çalışma, 3-5 Mayıs 2018 tarihleri arasında Alanya, Antalya/Türkiye'de gerçekleştirilen 4. Uluslararası Eğitim Bilimleri Sempozyumu'nda sözlü bildiri olarak sunulmuștur.

${ }^{* *}$ Dr. Öğr. Üyesi Fırat Üniversitesi, Eğitim Fakültesi, Matematik ve Fen Bilimleri Eğitimi Bölümü, Elazığ, Türkiye.

El-mek: f.erdogan@firat.edu.tr

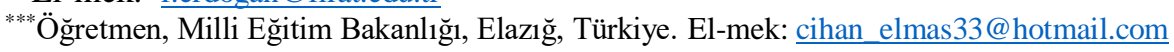




\begin{abstract}
It has been reported that one of the competencies that students need in personal, social, academic and business life is mathematical competence in mathematics curriculum. Mathematical competence includes the ability to use mathematical modes of thinking and presentation (formulas, models, fiction, graphics and tables) at different levels. For this purpose, it was aimed to investigate mathematical models usage of mathematics curriculum (Middle School $5^{\text {th }}-8^{\text {th }}$ Grades) in this research. Document analysis was used in qualitative research methods. The data of the study were obtained from the analysis of the mathematics curriculum published by Education and Training Board in 2018. During the data analysis process, learning areas, objectives and explanations for objectives in the mathematics curriculum were examined in terms of mathematical model usage (MMU). According to research findings, it has been determined that MMU was not included in sufficient level in the explanations for the objectives and objectives of the mathematics curriculum. Rather than the objectives, it was seen that MMU was given more place in explanations for objectives. It has been determined that MMU was most included in the eighth grade objectives, while MMU was found to be at least in the sixth and seventh grade objectives. It was also found that MMU was most involved in data processing learning area in fifth, seventh and eighth grade objectives. Moreover, in the sixth grade objectives of the MMU, it was determined that it took place mostly in the field of geometry and measurement learning.
\end{abstract}

Keywords: Mathematics curriculum, models, mathematical models, mathematics education

\title{
1. GİRIŞ
}

Günümüz işgücünün gerektirdiği beceriler belirgin bir şekilde değişmektedir. Bireylerin yeni bilgilere açık olmaları, yapılandırılmamış problemleri çözmeleri ve güçlü kişilerarası sosyal becerilere sahip olmaları ihtiyaç duyulan yetkinliklerdendir (Organisation for Economic Co-operation and Development [OECD], 2017). Bu bağlamda, matematik eğitiminin hedefleri arasında bireylere gerçek hayatta problem çözme becerilerinin kazandırılması vurgulanmakta ve matematiksel modellemenin de bu hedefe ulaşmada yardımcı bir öğe olduğu belirtilmektedir (Gravemeijer ve Stephan, 2002; Lesh ve Doerr, 2003).

Model, karmaşık sistem ve yapıları yorumlayıp anlamak için zihinde var olan kavramsal yapılar ve dışsal temsillerin bütünüdür. Dolayısıyla, modeller zihinsel yapılar olmalarının yanı sıra, öğrencilerin kullandıkları denklemler, tablolar, diyagramlar, bilgisayar programları gibi somutlaştırılmış dış gösterimlerle temsil edilen kavramsal sistemlerdir (Lesh ve Doerr, 2003). Ayrıca, model bir düşünce, bir nesne veya bir gerçek hayat durumunun görselleştirilmesidir (Gilbert, Boulter ve Elmer, 2000). Gerçek hayat durumlarının yorumlanıp anlamlandırılmasında modeller ile düşünme gerçekleşir (Lehrer ve Schauble, 2007). Matematiksel modeller ise gerçek hayatta yer alan bir nesne veya durumun fiziksel özelliklerinden ziyade daha çok yapısal özellikleri ve çalışma prensipleriyle ilgilidir (Lehrer ve Schauble, 2007; Lesh ve Doerr, 2003). Matematiksel model bir günlük hayat durumunun özelliklerinin formül, eşitlik, sembol, grafik, tablo ve şekil gibi matematiksel bir form aracılığılla gösterilmesidir (Kapur,1998). Ancak, matematiksel bir model gerçek hayat durumunun kapsadığı bütün özellikleri taşımakta zorunda değildir. Tek bir matematiksel gösterim de model olarak kabul edilmeyebilir. Bir 
gerçek hayat durumunun yapısını yansıtan farklı matematiksel gösterimler, fonksiyonel ilişkiler ve işlemler entegre olarak matematiksel modeli meydana getirmektedir (Erbaş ve diğerleri, 2014).

Modelleme, olayları ve problemleri yorumlama sürecinde bilinmeyen durumları zihinde organize etme, düzenleme, sistematik bir yapıya kavuşturma, ilişkiler arasında bir örüntü bulma ve açıklığa kavuşturup anlaşı1ır hale getirmek amacıyla yapılan işlemlerdir. Modelleme süreci, zihindeki farklı şemaları kullanarak modellerin ortaya çıkma sürecidir (Lesh ve Doerr, 2003; Treagust, 2002). Dolayısıyla, modelleme bir durumun veya problemin fiziksel, sembolik veya soyut modelini ortaya çıkarma süreci iken, model bu sürecin sonundaki ürün olarak görülebilir (Sriraman, 2006). Model ve modelleme yapısının içinde yer alan matematiksel modelleme, gerçek hayat problemlerinin soyutlama sürecinden sonra matematik diline aktarılması, çözümlenmesi ve çözümün değerlendirildiği döngüsel bir süreç olarak tanımlanmaktadır (Haines ve Crouch, 2007). Ayrıca, matematiksel modelleme bir gerçek hayat problemindeki olayları ve ilişkileri matematiksel olarak ifade etme, matematiksel örüntüleri ortaya çıkarma, analiz, sentez ve yorumlama gibi üstbilişsel becerilerin kullanıldığı sistematik bir süreci belirtmektedir (Swetz ve Hartzler, 1991; Verschaffel, Greer ve De Corte, 2002). Dolayısıyla, ögrenciler matematiksel modelleme sürecinde, gerçek hayat durumlarını matematiğin sembolik diline aktarırken aritmetik ve işlemsel bilgilerden ziyade uzamsal düşünme, analiz etme, yorumlama, ilişkilendirme, tahminde bulunma gibi üst düzey düşünme becerilerine ihtiyaç duymaktadır (Lehrer ve Schauble, 2003).

Son yıllarda, matematiksel modellemenin farklı seviyelerdeki öğretim kademelerinde kullanılması gerektiği düşüncesi önem kazanmıştır. Araştırma sonuçları, matematiksel modellemenin ögrencilerin gerçek hayat durumlarını matematiksel olarak anlamlandırmalarında yardımcı olduğunu göstermektedir (Swan, Turner, Yoon ve Muller, 2007; Zbiek ve Conner, 2006). Matematik öğretimi sürecinde modelleme uygulamalarıyla, matematikte anlamlı öğrenme gerçekleşir, matematik gerçek hayatla ilişkilendirilir, öğrencilerin gerçek hayat durumlarında problem çözme ve analitik düşünme becerileri gelişir (Erbaş ve diğerleri, 2014; Zbiek ve Conner, 2006). Modelleme etkinlikleriyle, ögrencilerin matematiksel tanımlamalar yapmaları, açıklamalarda bulunmaları, gerekçelendirme ve tartışmalar aracılığıyla düşüncelerinin gelişimi sağlanır (Lesh ve Doerr, 2003; Şahin ve Eraslan, 2016). Matematiksel modelleme, öğrencilerin mantıksal bağlantı kurmalarını ve matematiksel bilgiyi gerçek yaşamdaki problem durumlarına uygulayabilmelerini sağlar (Ferreira ve Jacobini, 2009; Schwarz ve Kaiser, 2007). Böylece, öğrencilerin matematiksel iletişim, tablo ve grafikleri kullanma becerileri de gelişmektedir (Didiş-Kabar ve İnan, 2018; English, 2006). Matematiksel modelleme, öğrencilerin sadece bilişsel veya üstbilişsel becerilerini değil aynı zamanda motivasyon (Blum ve Ferri, 2009) ve tutum (English, 2013; Isık ve Pilten, 2017; Kal, 2013) gibi duyuşsal çıktılarını da pozitif yönde etkilemektedir.

Matematiksel modellemenin öğretim sürecinde kullanılması matematik eğitimi açısından önemsenmektedir (National Council of Teachers of Mathematics [NCTM], 2000; Milli Eğitim Bakanlığı [MEB], 2018). Matematik Dersi Öğretim Programı'nda (MDÖP), öğrencilerden mantıksal ve 
uzamsal şekilde düşünmeleri, sunmanın (formüller, modeller, tablolar, grafikler ve kurgular) matematiksel durumlarını farklı derecelerde kullanma yetisi beklenmektedir (MEB, 2018). Güncellenen MDÖP’te matematiksel modelleme yapabilme becerisine vurgu yapıldığı görülmektedir. Son yıllarda matematik eğitimi alanında çeşitli seviyelerde öğrencilerle (Çiltaş, Demirci ve Güler, 2018; Doruk, 2012; Didiş-Kabar ve İnan, 2018; Hıdıroğlu ve Hıdıroğlu, 2017; Işık ve Pilten, 2017; Mumcu ve Baki, 2017; Şahin ve Eraslan, 2016, 2017) veya öğretmen adaylarıyla (Özdemir, Üzel ve Özsoy, 2017; Özer ve Bukova-Güzel, 2016; Urhan ve Dost, 2016; Yanık, Bağdat ve Koparan, 2017) matematiksel modelleme uygulamaları üzerine çalışmalar yapılmaktadır. Bu araştırmalarda çoğunlukla öğrencilerin veya öğretmen adaylarının matematiksel modelleme durumlarında düşünme süreçleri analiz edilmekte ve betimlenmektedir. Matematiksel modelleme becerisini geliştirmeye yönelik etkinliklerin tasarlanıp sunulduğu araştırmaların (Çiltaş ve Iş̧1k, 2013; Deniz ve Akgün, 2017; Yıldırım ve Işık, 2014) oldukça sınırlı olduğu görülmektedir. Bu doğrultuda, Türkiye'de matematiksel modellemenin öğretim sürecinde uygulamaları ve sonuçlarının değerlendirilmesine yönelik çalışmaların yeterli olmadığı söylenebilir.

Matematiksel modelleme kavramı PISA gibi uluslararası araştırmalarının matematik okuryazarlığı alanında öğrencilerin yeterlik düzeylerine ait çerçeveyi oluşturan önemli bir köşe taşıdır (OECD, 2003). PISA sınavlarında öğrencilerden beklenen matematik okuryazarlığı yeterlik düzeylerinde matematiksel modelleme bileşenlerine yer verilmektedir. PISA 2003 raporunda belirtilen altı seviyeden oluşan yeterlik düzeylerine bakıldığında, gösterim biçimleri yeterliğinin ikinci düzeyden itibaren öğrencilerin sahip olması beklenen önemli bir yeterlik olduğu görülmektedir (OECD, 2003). Ayrıca, PISA'daki problemlerin birçoğu modelleme sürecinin bazı aşamalarıyla doğrudan ilişkilidir. Bu yönüyle öğrencilerin uluslararası sınavlarda başarılı sonuçlar almaları için öğrencilerin matematiksel modelleme problemleriyle çalışacakları öğrenme ortamlarının oluşturulması önem taşımaktadır (Turner, 2007).

PISA 2015 sonuçlarına göre Türkiye, matematik okuryazarlığı alanında OECD ülkeleri arasında sondan ikinci sırada iken, 70 ülke arasında ise 49. sırada yer almaktadır (OECD, 2018). Bu durum, PISA sınavlarında Türkiye'deki öğrencilerin diğer ülkelere göre performanslarının oldukça düşük olduğunu göstermektedir. Ayrıca, PISA 2015 sonuçlarına göre, Türkiye'nin daha önceki yıllara göre matematik puanlarında düşüş olduğu belirlenmiştir (OECD, 2018).

Eğitim programının kazanımlar, içerik, eğitim durumları ve değerlendirme öğeleri içinde, kazanımların önemi büyüktür (Özdemir, Altık ve Baki, 2015). Kazanımların, öğretim sürecinin planlanmasına yardımcı olması ve sürece yön vermesi nedeniyle MDÖP kazanımlarını ele alan araştırmalar yapılmıştır. Alanyazın incelendiğinde, farklı yıllarda güncellenen MDÖP'lerin içerik, vizyon, yaklaşım, felsefe, öğrenme alanları ve kazanımlar olarak karşılaştırıldığı araştırmalar yapıldığı görülmektedir (Albayrak, 2017; Baş, 2017; Danişman ve Karadağ 2015; Şen, 2017). Nitekim, MDÖP’teki kazanımları, farklı açılardan sınıflandıran araştırmalar da mevcuttur. Bu araştırmalarda, MDÖP’te yer alan kazanımlar Bloom Taksonomisine göre (Çelik, Kul ve Çalık-Uzun, 2018; Kablan, Baran ve Hazer, 2013) veya TIMSS 2015 matematik çerçevesinde ifade edilen bilişsel alanlar ve alt 
boyutlara göre (İncikabı, Mercimek, Ayanoğlu, Aliustaoğlu ve Tekin, 2016) analiz edilmiştir. Bilen ve Çiltaş (2015) ise araştırmalarında MDÖP’ü öğretmen görüşlerine göre matematiksel model ve modelleme açısından incelemişlerdir. Araştırma bulgularına göre, öğretmenler, modellemenin ögrencilerin matematik tutumlarını, derse aktif katılımlarını ve kavramsal ögrenmelerini olumlu etkilediğini ifade etmişlerdir. Alanyazında yer alan araştırmalara bakıldığında, MDÖP'ü matematiksel model ve modelleme açısından inceleyen bir tek araştırmaya (Bilen ve Çiltaş, 2015) ulaşı1mıştır. MDÖP’ü çeşitli beceriler açısından inceleyen araştırmaların oldukça sınırlı sayıda olduğu görülmektedir. Ayrıca, uluslararası değerlendirme sınavlarında Türkiye'nin başarı düzeyinin, istenen seviyede olmadığı söylenebilir. MDÖP gelişen şartlara göre güncellenmesine rağmen Türkiye'nin matematik başarısının düşmesi bir problem durumu olarak karşımıza çıkmaktadır. MDÖP içeriğinin farklı boyutları ele alarak incelenmesi gerektiği düşünülmektedir. Matematiksel modellemenin uluslararası sınavlarda ölçülen hem problem çözme hem de matematik okuryazarlığı becerileriyle ilişkisi göz önüne alınarak MDÖP'nin matematiksel model kullanımı bağlamında incelenmesi önemli görülmektedir. Yapılan bu araştırmanın MDÖP inceleme çalışmalarına katkı sağlayacağı ve matematik eğitimi alanyazınında önemli bir boşluğu dolduracağı düşünülmektedir. Bu araştırmada MDÖP'ün (Ortaokul 5-8. sınıflar) matematiksel model kullanımı bağlamında incelenmesi amaçlanmıştır. Belirlenen amaç doğrultusunda “MDÖP’teki kazanımların ve kazanımlara yönelik açılamaların matematiksel model kullanımı bazında dağılımı nasıldır?" sorusu araştırma problemi olarak belirlenmiştir. Araştırmanın alt problemleri ise aşağıdaki şekildedir:

1. MDÖP’teki kazanımların ve kazanımlara yönelik açıklamaların matematiksel model kullanımı bazında sınıf seviyelerine göre dağılımı nasıldır?

2. Beşinci, altıncı, yedinci ve sekizinci sınıf seviyesindeki kazanımların ve kazanımlara yönelik açıklamaların matematiksel model kullanımı bazında öğrenme alanlarına göre dağılımı nasıldır?

\section{YÖNTEM}

\section{Model}

$\mathrm{Bu}$ araştırmada nitel araştırma yöntemlerinden doküman analizi kullanılmıştır. Nitel araştırmalarda doküman analizi diğer veri toplama yöntemleri ile kullanılabileceği gibi tek başına bir yöntem olarak da kullanılabilir (Bowen, 2009). Doküman analizi, araştırılması amaçlanan olgu veya olgularla ilgili bilgilerin yer aldığı yazılı materyallerin analiz edilmesidir. Doküman analizi yönteminde, eğitim alanında yapılan çalışmalarında genellikle ders kitabı ve öğretim programları veri kaynağı olarak ele alınır (Yıldırım ve Şimşek, 2008). Bu araştırmada, nitel yöntem bağlamında doküman analizi yapılarak MDÖP matematiksel model kullanımı açısından betimlenmiştir.

\section{Veri Toplama}


Araştırmada, MDÖP'ü matematiksel model kullanımı (MMK) bağlamında incelemek amaçlandığından, bu amacına uygun olarak veriler doküman analizi ile toplanmıştır. Araştırma kapsamında incelenen döküman MEB tarafından 2018 yılında Talim Terbiye Kurulunca yayımlanan MDÖP'tür. Araştırmanın verileri MDÖP'ün ortaokul 5, 6, 7 ve 8. sınıfları içeren bölümünün analizinden elde edilmiştir.

\section{Veri Analizi}

Araştırmada veriler betimsel olarak analiz edilmiştir. Veri analizi sürecinde MDÖP’te yer alan kazanımlar ve kazanımlara yönelik açıklamalar MMK bakımından incelenmiştir. Çalışmanın analiz kısmında şu aşamalar takip edilmiştir. Araştırma verilerini kodlama sürecine geçmeden önce matematik eğitimi alanında matematiksel modelin ve modellemenin anlamı, tanımı, amacı, öğretim programıla bütünleştirilme şekliyle ilgili alanyazın taraması yapılmıştır (Berry ve Houston, 1995; Gilbert ve Boulter, 1998; Gilbert ve diğerleri, 2000; Kapur, 1998; Lehrer ve Schauble, 2007; Lesh ve Doerr, 2003; OECD, 2003; Taş, Arıcı, Ozarkan ve Özgürlük, 2016). Alanyazın taraması sonunda matematiksel model kavramıyla ilgili anahtar kelimeler (model, gerçek hayat durumu, tablo, grafik, diyagram, şekil, sembol, gösterim, temsil, bağıntı) belirlenmiştir. Bu anahtar kelimelerin oluşturulması sürecinde üç farklı devlet üniversitesinde matematik eğitimi anabilim dalında görev yapan ve matematiksel modelleme konusunda çalışmaları bulunan alan uzmanlarının ( 2 profesör, 1 doçent, 1 yardımcı doçent) görüşleri alınmıştır.

Alanyazına dayalı anahtar kelimelerin belirlenmesinin ardından MDÖP'ün ortaokul 5, 6, 7 ve 8 . sınıflar bölümüne ait kazanımlar ve kazanımlara yönelik açıklamalar iki araştırmacının her biri tarafından bağımsız olarak kodlanmıştır. Kazanımlarla ilgili anahtar kelimeler belirlenmesinin yanında, kazanımlar ve kazanımlara yönelik yapılan açıklamalar bütüncül olarak değerlendirilmiştir. Kazanımda ifade edilmek istenen anlam da göz önüne alınmıştır. Dolayısıyla, kodlamalar "Kazanımlar ve Kazanımlara Yönelik Açıklamalar” başlı̆̆ı temel alınarak sınıf seviyeleri alt başlıklarına göre betimlenmiştir. Kodlamalar sonucu araştırmacılar arası uyum yüzdesi (Miles ve Huberman, 1994) hesaplanmış ve kodlayıcılar arası güvenirlik katsayısı 0.98 olarak bulunmuştur. Bu sonuç araştırma için güvenilirdir (Miles ve Huberman, 1994). Ancak, uyuşmazlığa neden olan kodlar üzerinde tekrar görüşülmüş ve fikir birliğine varılmıştır. Sonuçlar frekanslar ve yüzdeler halinde betimsel istatistik bulgularıly birlikte verilmiştir.

\section{BULGULAR}

Bu bölümde, MDÖP’te yer alan kazanımlar ve kazanımlara yönelik açıklamalar sınıf ve alt öğrenme alanları göre MMK bazında incelenip sonuçlar frekans ve yüzdeler halinde betimleyici şekilde verilmiştir. 
MDÖP’te yer alan kazanımların ve kazanımlara yönelik açıklamaların sınıf seviyelerine göre MMK bazında sınıflandırması Tablo 1'de verilmiştir.

Tablo 1. Kazanımlar ve Kazanımlara Yönelik Açıklamalarda Yer Alan MMK'nın Sınıf Seviyelerine Göre Dağılımı

\begin{tabular}{ccccccc}
\hline Sinıf & $\begin{array}{c}\text { Kazanım } \\
\text { sayısı }\end{array}$ & $\begin{array}{c}\text { MMK içeren } \\
\text { kazanım } \\
\text { sayısı }\end{array}$ & $\begin{array}{c}\text { Kazanımlara yönelik } \\
\text { açıklama sayısı }\end{array}$ & $\begin{array}{c}\text { MMK içeren } \\
\text { kazanımlara yönelik } \\
\text { açıklama sayısı }\end{array}$ & $\%$ \\
\hline 5 & 56 & 16 & 29 & 78 & 29 & 37 \\
\hline 6 & 59 & 11 & 19 & 65 & 14 & 34 \\
\hline 7 & 48 & 9 & 19 & 57 & 32 & 36 \\
\hline 8 & 52 & 17 & 33 & 89 & 97 & 34 \\
\hline Toplam & 215 & 53 & 25 & 289 & & 22 \\
\hline
\end{tabular}

Tablo 1 incelendiğinde, tüm sınıf seviyelerinde toplam 215 kazanım ifadesinin 53'ünde (\% 25), toplam 289 tane kazanımlara yönelik açıklamanın 97 tanesinde (\% 34) MMK’ye yer verildiği görülmektedir. MMK'nın en çok sekizinci (\% 33), en az ise altıncı ve yedinci sınıf (\% 19) kazanımlarında yer aldığı görülmektedir. Kazanımlara yönelik açıklamalar incelendiğinde ise MMK'nın en çok beşinci sınıf (\% 37), en az yedinci sınıf (\% 25) seviyelerinde yer aldığı tespit edilmiştir. Farklı Sınıf Seviyelerindeki Kazanımların ve Kazanımlara Yönelik Açıklamaların MMK Bazında Öğrenme Alanlarına Göre Dağılımına İlişkin Bulgular

MDÖP’teki kazanımlar ve kazanımlara yönelik açıklamaların beşinci sınıf seviyesinde MMK bazında öğrenme alanlarına göre dağılımları incelenmiş ve bulgular Tablo 2'de sunulmuştur.

Tablo 2. Beşinci Sınıf Seviyesinde, Kazanımlar ve Kazanımlara Yönelik Açıklamalarda Yer Alan MMK'nın Dağılımı

\begin{tabular}{lcccccc}
\hline Öğrenme alanı & $\begin{array}{c}\text { Kazanım } \\
\text { sayısı }\end{array}$ & $\begin{array}{c}\text { MMK içeren } \\
\text { kazanım } \\
\text { sayısı }\end{array}$ & $\%$ & $\begin{array}{c}\text { Kazanımlara } \\
\text { yönelik açıklama } \\
\text { sayısı }\end{array}$ & $\begin{array}{c}\text { MMK içeren } \\
\text { kazanım açıklama }\end{array}$ & sayısı \\
\hline Sayılar ve işlemler & 33 & 12 & 36 & 39 & 22 & 56 \\
\hline Geometri ve ölçme & 20 & 2 & 10 & 34 & 2 & 15 \\
\hline Veri işleme & 3 & 2 & 67 & 5 & 29 & 37 \\
\hline Toplam & 56 & 16 & 29 & 78 & 5 \\
\hline
\end{tabular}

Tablo 2'ye göre, beşinci sınıf seviyesinde toplam 56 kazanımın 16'sında (\% 29), toplam 78 kazanımlara yönelik açıklamanın 29'unda (\% 37) MMK'nın yer aldığı görülmektedir. Beşinci sınıf kazanımlarında MMK'nın en çok veri işleme (\% 67), en az geometri ve ölçme (\% 10) öğrenme alanında yer aldığı tespit edilmiştir. Kazanımlara yönelik açıklamalara ait bulgular incelendiğinde, en çok sayılar ve işlemler (\% 56), en az geometri ve ölçme (\% 15) öğrenme alanında MMK'nın yer aldığı belirlenmiştir. Beşinci sınıf seviyesinde MMK'nın yer aldığı örnek kazanım ve kazanıma yönelik 
açıklama şunlardır: "Bir yüzdelik ifadeyi aynı büyüklüğü temsil eden kesir ve ondalık gösterimle ilişkilendirir, bu gösterimleri birbirine dönüştürür. $\mathrm{Bu}$ sayıları gerçek hayatla ilişkilendirme durumlarında karşılaştırma ve anlamlandırmaya yönelik çalışmalara yer verilir.” (MEB, 2018).

MDÖP’teki kazanımlar ve kazanımlara yönelik açıklamaların altıncı sınıf seviyesinde MMK bazında öğrenme alanlarına göre dağılımları analiz edilmiş ve bulgular Tablo 3 'te verilmiştir.

Tablo 3. Altıncı Sınıf Seviyesinde, Kazanımlar ve Kazanımlara Yönelik Açıklamalarda Yer Alan MMK'nın Dağılımı

\begin{tabular}{lcccccc}
\hline Öğrenme alanı & $\begin{array}{c}\text { Kazanım } \\
\text { sayısı }\end{array}$ & $\begin{array}{c}\text { MMK içeren } \\
\text { kazanım } \\
\text { sayısı }\end{array}$ & $\begin{array}{c}\% \\
\text { Kazanımlara } \\
\text { yönelik } \\
\text { açıklama sayısı }\end{array}$ & $\begin{array}{c}\text { MMK içeren } \\
\text { kazanım açıklama } \\
\text { sayııı }\end{array}$ & $\%$ \\
\hline Sayılar ve işlemler & 32 & 6 & 19 & 37 & 15 & 41 \\
Geometri ve ölçme & 19 & 4 & 21 & 20 & 4 & 20 \\
Veri işleme & 5 & 1 & 20 & 4 & 1 & 25 \\
Cebir & 3 & 0 & 0 & 4 & 2 & 50 \\
Toplam & 59 & 11 & 19 & 65 & 22 & 34 \\
\hline
\end{tabular}

Tablo 3 analiz edildiğinde, altıncı sınıf seviyesinde toplam 59 kazanımın 11 'inde (\% 19), toplam 65 kazanımlara yönelik açıklamanın 22'sinde (\% 34) MMK'nın yer aldığı görülmektedir. Altıncı sınıf kazanımlarında MMK'nın en çok geometri ve ölçme (\% 21), en az cebir (\% 0) öğrenme alanında yer aldığı tespit edilmiştir. Kazanımlara yönelik açıklamalara ait bulgular ele alındığında, en çok cebir (\% 50), en az geometri ve ölçme (\% 20) öğrenme alanında MMK’nın yer aldığı belirlenmiştir. Cebir öğrenme alanında MMK'nın yer aldığı kazanım oranı en az iken, kazanımlara yönelik açıklama oranının en çok olduğu saptanmıştır. Altıncı sınıf seviyesinde MMK'nın yer aldığı örnek kazanım ve kazanıma yönelik açıklama şunlardır: "İki gruba ait verileri ikili sıklık tablosu ve sütun grafiği ile gösterir. Gerçek hayat durumları ve uygun kesir modelleriyle yapılacak çalısmalara yer verilir.” (MEB, 2018).

MDÖP’teki kazanımlar ve kazanımlara yönelik açıklamaların yedinci sınıf seviyesinde MMK bazında öğrenme alanlarına göre dağılımları incelenmiş ve bulgular Tablo 4'te verilmiştir.

Tablo 4. Yedinci Sınıf Seviyesinde, Kazanımlar ve Kazanımlara Yönelik Açıklamalarda Yer Alan MMK'nın Dağılımı

\begin{tabular}{|c|c|c|c|c|c|c|}
\hline Öğrenme alanı & $\begin{array}{r}\text { Kazanım } \\
\text { sayıs1 }\end{array}$ & $\begin{array}{r}\text { MMK } \\
\text { içeren } \\
\text { kazanım } \\
\text { sayısı }\end{array}$ & $\%$ & $\begin{array}{r}\text { Kazanımlara } \\
\text { yönelik } \\
\text { açıklama sayısı }\end{array}$ & $\begin{array}{r}\text { MMK içeren } \\
\text { kazanım açıklama } \\
\text { sayısı }\end{array}$ & $\%$ \\
\hline Sayılar ve işlemler & 25 & 4 & 15 & 28 & 7 & 28 \\
\hline Geometri ve ölçme & 12 & 1 & 8 & 15 & 1 & 7 \\
\hline Veri işleme & 4 & 3 & 75 & 4 & 3 & 75 \\
\hline Cebir & 7 & 1 & 14 & 10 & 3 & 30 \\
\hline Toplam & 48 & 9 & 19 & 57 & 14 & 25 \\
\hline
\end{tabular}


Tablo 4'e bakıldığında, yedinci sınıf seviyesinde toplam 48 kazanımın 9'unda (\% 19), toplam 57 kazanımlara yönelik açıklamanın 14'ünde (\% 25) MMK'nın yer aldığı görülmektedir. Yedinci sınıf kazanımlarında MMK'nın en çok veri işleme (\% 75), en az geometri ve ölçme (\% 8) öğrenme alanında yer aldığı belirlenmiştir. Kazanımlara yönelik açıklamalara ait bulgulara göre, en çok veri işleme (\% 75), en az geometri ve ölçme (\% 7) öğrenme alanında MMK'nın yer aldığı saptanmıştır. Yedinci sınıf seviyesinde MMK'nın yer aldığı örnek kazanım ve kazanıma yönelik açıklama şunlardır: "Gerçek hayat durumlarını inceleyerek iki çokluğun ters orantılı olup olmadığına karar verir. Tam sayıların kullanıldığı asansör, termometre gibi araçlar yatay, dikey sayı doğrusu gibi modellerle ilişkilendirilerek toplama ve çıkarma işlemlerine yer verilir.” (MEB, 2018).

MDÖP’teki kazanımlar ve kazanımlara yönelik açıklamaların sekizinci sınıf seviyesinde MMK bazında öğrenme alanlarına göre dağılımları incelenmiş ve bulgular Tablo 5’te sunulmuştur.

Tablo 5. Sekizinci Sınıf Seviyesinde, Kazanımlar ve Kazanımlara Yönelik Açıklamalarda Yer Alan MMK'nın Dağılımı

\begin{tabular}{lcccccc}
\hline Öğrenme alanı & $\begin{array}{c}\text { Kazanım } \\
\text { sayısı }\end{array}$ & $\begin{array}{c}\text { MMK içeren } \\
\text { kazanım } \\
\text { sayıs }\end{array}$ & $\%$ & $\begin{array}{c}\text { Kazanım } \\
\text { yönelik } \\
\text { açıklama sayısı }\end{array}$ & $\begin{array}{c}\text { MMK içeren } \\
\text { kazanım açıklama } \\
\text { sayısı }\end{array}$ & $\%$ \\
\hline Sayılar ve işlemler & 16 & 2 & 13 & 13 & 3 & 21 \\
\hline Geometri ve ölçme & 16 & 6 & 38 & 41 & 1 & 51 \\
\hline Veri işleme & 2 & 2 & 100 & 1 & 6 & 100 \\
\hline Cebir & 13 & 7 & 54 & 24 & 32 & 3 \\
\hline Olasılık & 5 & 0 & 0 & 10 & 89 & 36 \\
\hline Toplam & 52 & 17 & 33 & 89 & 10 \\
\hline
\end{tabular}

Tablo 5'e göre, sekizinci sınıf seviyesinde toplam 52 kazanımın 17'sinde (\% 33), toplam 89 kazanımlara yönelik açıklamanın 32'sinde (\% 36) MMK'nın yer aldığı görülmektedir. Sekizinci sınıf kazanımlarında MMK'nın en çok veri işleme (\% 100), en az olasılık (\% 0) öğrenme alanında yer aldığı tespit edilmiştir. Kazanımlara yönelik açıklamalara ait bulgulara bakıldığında, en çok veri işleme (\% 100), en az olasılık (\% 10) öğrenme alanında MMK'nın yer aldığı belirlenmiştir. Veri işleme öğrenme alnında hem kazanım hem de kazanımlara yönelik açıklamalarda \% 100 oranında MMK yer verilmesi dikkat çekici bir bulgudur. Sekizinci sınıf seviyesinde MMK'nın yer aldığı örnek kazanım ve kazanıma yönelik açıklama şunlardır: Birinci dereceden bir bilinmeyenli eşitsizlik içeren günlük hayat durumlarına uygun matematik cümleleri yazar. Pisagor bağıntısının gerçek hayat uygulamalarına yönelik çalışmalara yer verilir (MEB, 2018).

\section{TARTIŞMA, SONUÇ VE ÖNERILER}

$\mathrm{Bu}$ araştırma kapsamında, MDÖP'ün (Ortaokul 5-8. sınıflar) MMK bağlamında incelenmesi amaçlanmıştır. Araştırmanın birinci alt problemine dayanarak, MDÖP’teki kazanımların ve kazanımlara yönelik açıklamaların MMK bazında sınıf seviyelerine göre dă̆ılımı analiz edilmiştir. Araştırmada 
ortaya çıkan sonuçlara göre, MMK'nın en çok sekizinci, en az ise altıncı ve yedinci sınıf kazanımlarında yer aldığı saptanmıştır. Kazanımlara yönelik açıklama bulgularına göre, MMK'nın en çok beşinci sınıf, en az yedinci sınıf seviyelerinde yer aldığı belirlenmiştir. Araştırma bulgularına göre, MDÖP’te hem kazanımlarda hem de kazanımlara yönelik açıklamalarda MMK'ye yeterli seviyede yer verilmediği belirlenmiştir. Kazanımlardan ziyade, kazanımlara yönelik yapılan açıklamalarda MMK'ye daha çok yer verildiği görülmüştür.

Araştırmanın ikinci alt problemi kapsamında, MDÖP’teki farklı sınıf seviyelerindeki kazanımlar ve kazanımlara yönelik açıklamalar MMK bazında öğrenme alanlarına göre dağılımı incelenip sonuçlar ortaya konulmuştur. Bu sonuçlara göre, beşinci, yedinci ve sekizinci sınıf kazanımlarında MMK'nın en çok veri işleme öğrenme alanında, altıncı sınıf kazanımlarında ise en çok geometri ve ölçme öğrenme alanında yer aldığı belirlenmiştir. Sınıf seviyelerine göre kazanımlarda MMK'nın en az yer aldığı öğrenme alanları; beşinci ve yedinci için geometri ve ölçme, altıncı sınıf için cebir, sekizinci sınıf için olasılık öğrenme alanıdır.

Kazanımlara yönelik yapılan açıklamaların incelendiği araştırma sonuçları ise, beşinci ve altıncı sınıf seviyelerinde en çok sayılar ve işlemler; yedinci ve sekizinci sınıf seviyelerinde ise en çok veri işleme öğrenme alanında MMK'nın yer aldığını göstermektedir. Sınıf seviyelerine göre kazanımlara yönelik açıklamalarda MMK'nın en az yer aldığı öğrenme alanları; beşinci, altıncı ve yedinci sınıf için geometri ve ölçme, sekizinci sınıf için olasılık öğrenme alanıdır. Özellikle geometri öğrenme alanında öğrencilerin geometrik yapı ve kavramları soyutlaştırarak anlamlı öğrenmeler gerçekleştirmelerinde MMK'nın önemli olacağı düşünülmektedir. Ancak, hem kazanımlarda hem de kazanımlara yönelik açıklamalarda geometri öğrenme alanında MMK'ye yeterince yer verilmediği görülmüştür. Program geliştirme çalışmalarında bu durumun göz önüne alınarak MMK'ye daha çok yer verilmesi önerilmektedir. NCTM'nin (2000) görüşü de bu öneriyi desteklemektedir. NCTM (2000) raporunda, matematik derslerinde model kullanımı ve modelleme etkinliklerine daha fazla yer verilmesi gerektiğini vurgulamaktadır. Araştırmanın bulguları, Ferri ve Blum'un (2013) araştırma sonuçlarını desteklemektedir. Ferri ve Blum (2013) araştırmalarında matematiksel modellemenin matematik öğretimi sürecine entegrasyonuyla ilgili çalışmalar ve revizyonlar yapılmasına rağmen matematiksel modellemenin sınıf içi uygulamalarda çok az yer bulduğunu belirtmektedir.

Ortaokul dönemi soyut düşünmenin geliştiği önemli bir süreçtir. Ortaokul döneminde matematiksel modelleme etkinlikleri, gerçek hayattan matematiğin soyut kavramlarına geçiş için önemli bir unsur olarak görülmektedir (Hıdıroğlu ve Hıdıroğlu, 2017). Bu bağlamda, matematik dersinin içeriğini belirleyen ve öğretmenlere yol gösterici bir araç niteliğinde olan MDÖP kazanımlarında matematiksel model ve modelleme ifadelerine, etkinlik örneklerine, modellemeyle ilgili açıklamalara daha çok yer verilmesi önerilmektedir.

$\mathrm{Bu}$ araştırmada MDÖP'ün (Ortaokul 5-8. sınıflar) kazanımları ve kazanımlara yönelik açıklamaları MMK bağlamında incelenmiştir. Yapılacak araştırmalarda, matematik ders kitaplarının içeriği matematiksel modelleme bağlamında incelenebilir. Nitekim, matematiksel modelleme ile ilgili 
problemlerin rutin olmayan yapıda olması, zenginleştirilmiş bilgileri, farklı durumları ve bilişsel süreçleri kapsaması önemlidir (Eric, 2009). Bu doğrultuda, matematik ders kitaplarında yer alan problemlerin matematiksel modelleme prensiplerine sahip olmaları bakımından ayrıntılı nitel analizleri yapılabilir. Ayrıca, Türkiye'deki MDÖP'ün uluslararası yerini belirleyebilmek amacıyla, uluslararası TIMSS, PISA gibi sınavlarda başarılı olan ülkelerin programları MMK bağlamında karşıllaştırmalı olarak incelenebilir.

Matematiksel modelleme etkinliklerinin öğrencilerin matematik okuryazarlık seviyelerini yükselteceği ve matematiği günlük hayatla ilişkilendirerek daha anlamlı öğrenmeler gerçekleştirmede etkin bir rol oynayacağı belirtilmektedir (Erbaş ve diğerleri, 2014). Ancak, Türkiye'de yapılan araştırma sonuçları matematik öğretmenlerinin matematiksel modelleme etkinlikleri hakkında yeterince bilgiye sahip olmadığını ve dolayısıyla matematiksel modellemeyi matematik ders işleme sürecinde etkili bir şekilde kullanmadığını ortaya koymuştur (Akgün, Çiltas, Deniz, Bayrakdar-Çiftçi ve Işık, 2013; Özdemir ve diğerleri, 2017; Özer ve Bukova-Güzel, 2016; Urhan ve Dost, 2016). Matematik programlarındaki revizyonlara rağmen matematiksel model ve modellemenin sınıf içi uygulamalarda yeterince yer almamasının nedenlerinden biri, matematik öğretmenlerinin matematiksel model kavramına yabancı olmalarıdır (Blum, 2002; Frejd, 2012; Yu ve Chang, 2011). Bu bağlamda, sınıflarda modelleme etkinliklerini uygulayacak olan öğretmenlerin matematiksel model ve modellemeye yönelik bilgi ve becerilerini geliştirmeye yönelik deneysel araştırmalar yapılması ve sonuçlarının irdelenmesi önerilmektedir.

\section{KAYNAKÇA}

Akgün, L., Çiltas, A., Deniz D., Bayrakdar Çiftçi, Z., \& Işık, A. (2013). İlköğretim matematik öğretmenlerinin matematiksel modelleme ile ilgili farkındalıkları. Adlyaman Üniversitesi Sosyal Bilimler Enstitüsü Dergisi, 12, 1-34.

Albayrak, M. (2017). 1990 ve 2017 ilkokul matematik dersi öğretim programlarının değerlendirilmesi. Ahi Evran Üniversitesi Kırşehir Ë̆itim Fakültesi Dergisi, 18 (3), 685-701.

Baş, M. (2017). 2009 ve 2015 ilkokul matematik dersi öğretim programları ile 2017 ilkokul matematik dersi öğretim programı karşılaştırması. YYÜ Eğitim Fakültesi Dergisi, 14 (1), 1219-1258.

Berry, J. \& Houston, K. (1995). Mathematical modelling. Bristol: J. W. Arrowsmith Ltd.

Bilen, N. ve Çiltaş, A. (2015). Ortaokul matematik dersi beşinci sınıf öğretim programı'nın öğretmen görüşlerine göre matematiksel model ve modelleme açısından incelemesi. Kafkas Eğitim Araştırmaları Dergisi, 2 (2), 40-54.

Blum, W. (2002). ICMI Study 14: Applications and modelling in mathematics education -Discussion document. Educational Studies in Mathematics, 51, 149-171.

Blum, W. \& Ferri, R. B. (2009). Mathematical modeling: Can it be taught and learnt? Journal of Mathematical Modeling and Applications, 1 (1), 45-58. 
Bowen, A. G. (2009). Document analysis as a qualitative research method. Qualitative Research Journal, 9 (2), 27-40.

Çelik, S., Kul, Ü. \& Çalık Uzun, S. (2018). Ortaokul matematik dersi öğretim programındaki kazanımların yenilenmiş Bloom taksonomisine göre incelenmesi. Abant İzzet Baysal Üniversitesi Eğitim Fakültesi Dergisi, 18 (2), 775-795.

Çiltaş, A., Demirci, G., \& Güler, G. (2018). 7. sınıf öğrencilerinin zekâ türlerine göre matematiksel modelleme problemi çözebilme becerilerinin incelenmesi. Atatürk Üniversitesi Sosyal Bilimler Enstitüsü Dergisi, 22 (2), 889-903.

Çiltaş, A. ve Işık A. (2013). Matematiksel modelleme yoluyla öğretimin ilköğretim matematik öğretmeni adaylarının modelleme becerileri üzerine etkisi. Kuram ve Uygulamada Eğitim Bilimleri, 13, 1177 1194.

Danişman, Ş. ve Karadağ, E. (2015). Öğrenme alanları ve kazanımlar bağlamında 2005 ve 2013 beşinci sınıf matematik öğretim programlarının karşılaştırılması. Turkish Journal of Computer and Mathematics Education, 6 (3), 380-398.

Deniz, D. ve Akgün, L. (2017). Ortaöğretim matematik öğretmenlerinin matematiksel modelleme yöntemi ve uygulamalarına yönelik görüşleri. Muş Alparslan Üniversitesi Sosyal Bilimler Dergisi, 5 (1), 95-117.

Didiş-Kabar, M. G., \& İnan, M. (2018). Ortaokul yedinci sınıf öğrencilerinin matematikselleştirme süreçleri ve matematiksel modellerinin incelenmesi: Çim biçme problemi. Türk Bilgisayar ve Matematik Ë̆itimi Dergisi, 9 (2), 339-366.

Doruk, B. K. (2012). Değerler eğitimi için kullanışlı bir araç olarak matematiksel modelleme etkinlikleri. Kuram ve Uygulamada Eğitim Bilimleri, 12 (2), 1653-1672.

English, L. D. (2006). Mathematical modeling in the primary school: Children's construction of a consumer guide, Educational Studies in Mathematics, 63 (3), 303-323.

English, L. D. (2013). Complex modelling in the primary and middle school years: An interdisciplinary approach. In G. A. Stillman, G. Kaiser, W. Blum \& J. P. Brown (Eds.), Teaching mathematical modelling: Connecting to research and practice (pp. 491-505). Dordrecht: Springer.

Erbaş A., Kertil, M., Çetinkaya, B., Çakıroğlu, E., Alacacı, C., \& Baş, S. (2014). Matematik eğitiminde matematiksel modelleme: temel kavramlar ve farklı yaklaşımlar. Educational Sciences: Theory \& Practice, 14 (4), 1-21.

Eric, C. C. M. (2009). Mathematical modelling as problem solving for children in the Singapore mathematics classrooms. Journal of Science and Mathematics Education in Southeast Asia, 32 (1), 36-61.

Ferreira, L. H. D. \& Jacobini, O. R. (2009). Mathematical modelling: From classroom to the real world. In M. Blomhøj, \& S. Carreira (Ed.), Mathematical applications and modelling in the teaching and learning of mathematics (pp. 35-46). Roskilde: Roskilde University. 
Ferri, R. B. \& Blum, W. (2013). Barriers and motivations of primary teachers for implementing modelling in mathematics lessons. Eighth Congress of European Research in Mathematics Education (CERME 8), Antalya, Turkey.

Frejd, P. (2012). Teachers' conceptions of mathematical modelling at Swedish Upper Secondary school. Journal of Mathematical Modelling and Application, 1 (5), 17-40.

Gilbert, J. \& Boulter, C. (1998). Models in explanations, Part 1: Horses for courses? International Journal Science Education, 20 (1), 83-97.

Gilbert, J. K., Boulter, C.J. \& Elmer, R. (2000). Positioning models in science education and indesign and technology education. In J.K. Gilbert \& C.J. Boulter (Eds.), Developing models in science education (pp. 3-18). Dordrecht: Kluwer Academic Publishers

Gravemeijer, K., \& Stephan, M. (2002). Emergent models as an instructional design heuristic. In K. Gravemeijer, R. Lehrer, B. Oers, \& L. Verschaffel (Eds.), Symbolizing, modeling and tool use in mathematics education (pp. 145-169). Dordrecht, The Netherlands: Kluwer Academic Publishers.

Haines, C. \& Crouch, R. (2007). Mathematical modeling and applications: Ability and competence frameworks. In W. Blum, P. L. Galbraith, H. Henn, \& M. Niss (Eds.), Modelling and applications in mathematics education: The 14th ICMI study (pp. 417-424). New York, NY: Springer.

Hıdıroğlu, Ç. N. ve Hıdıroğlu, Y. Ö. (2017). Altıncı sınıf öğrencilerinin matematiksel modellemede oluşturdukları gerçek yaşam problem durumu modelleri. İlköğretim Online, 16(4), 1702-1731.

Is1k N. ve Pilten P. (2017). The effects of mathematical modelling activities on the difficulty perception of numbers sense and achievement among 4th graders. European Journal of Education Studies, 3(1), 91-111.

İncikabı, L., Ayanoğlu, P., Aliustaoğlu, F., Tekin, N. \& Mercimek, O. (2016). Ortaokul matematik dersi öğretim programı kazanımlarının Tımss bilişsel alanlarına göre değerlendirilmesi. İlköğretim Online, 15(4), 1149-1163.

Kablan, Z., Baran, T., \& Hazer, Ö. (2013). İlköğretim matematik 6-8 öğretim programında hedeflenen davranışların bilişsel süreçler açısından incelenmesi. Ahi Evran Üniversitesi Kırşehir Eğitim Fakültesi Dergisi (KEFAD), 14 (1), 347-366.

Kal, F. M. (2013). Matematiksel modelleme etkinliklerinin ilköğretim 6. sinıf ögrencilerinin problemi çözme tutumlarına etkisi. Yayımlanmamış yüksek lisans tezi. Kocaeli Üniversitesi, Fen Bilimleri Enstitüsü, Kocaeli.

Kapur, J. N. (1998). Mathematical modeling. New Delhi: New ageinternational(P) Ltd.,Publishers.

Lehrer, R. \& Schauble, L. (2007). A developmental approach for supporting the epistemology of modeling. In W. Blum, P. L. Galbraith, H-W. Henn, \& M. Niss (Eds.), Modeling and applications in mathematics education (pp. 153-160). New York, NY: Springer.

Lesh, R. \& Doerr, H. M. (2003). Foundations of a models and modeling perspective on mathematics teaching, learning, and problem solving. In R. Lesh, \& H. M. Doerr (Eds.), Beyond constructivism: 
Models and modeling perspectives on mathematics problem solving, learning, and teaching (pp. 333). Mahwah, NJ: Lawrence Erlbaum.

Miles, B., M. \& Huberman, A., M. (1994). Qualitative data analysis (21nd ed.). London: Sage Publication.

Milli Eğitim Bakanlığı (2018). Matematik dersi öğretim programı (İlkokul ve ortaokul 1, 2, 3, 4, 5, 6, 7 ve 8. Sinıflar). Ankara: MEB Yayınları.

Mumcu, H. Y. ve Baki, A. (2017). Matematiği kullanma aktivitelerinde lise öğrencilerinin matematiksel modelleme becerilerinin yorumlanması. OMÜ Ĕgt. Fak. Derg., 36(1), 7-33.

National Council of Teachers of Mathematics. (2000). Principles and standards for school mathematics. Reston, VA: Author.

Organization for Economic Co-operation and Development. (2003). The PISA 2003 assessment framework. Çevrimiçi:http://www.oecd.org/edu/school/programmepisa/33694881.pdf. Erişim tarihi: 23 Kasım 2017.

Organization for Economic Co-operation and Development. (2017). PISA 2015 results (Volume V): Collaborative problem solving, PISA. Paris: OECD Publishing.

Organization for Economic Co-operation and Development. (2018). PISA 2015 results in focus. Çevrimiçi: https://www.oecd.org/pisa/pisa-2015-results-in-focus.pdf. Erişim tarihi: 15 Haziran 2018.

Özdemir, E., Üzel, D. \& Özsoy, N. (2017). An investigation of teachers' views on applicability of modeling in mathematics courses. Journal of Education and Training Studies, 5 (5), 145-155.

Özdemir, S. M., Altık, S., \& Baki, N. (2015). Bloom'un yenilenmiş taksonomisine göre sosyal bilgiler öğretim programı kazanımlarının incelenmesi. Ĕgitim ve Öğretim Araştırmaları Dergisi, 4 (3), 363 375.

Özer, A. Ö. ve Bukova Güzel, E. (2016). Öğrenci, öğretmen adayı ve öğretmenlerin bakış açısından matematiksel modelleme problemleri. Manisa Celal Bayar Üniversitesi Eğitim Fakültesi Dergisi, 4 (1), 57-73.

Schwarz, B. \& Kaiser, G. (2007). Mathematical modelling in school - experiences from a project integrating school and university.[Çevrimiçi: http://www.erzwiss. unihamburg.de/personal/gkaiser/pdf-publist/cerme5_ Schwarz-kaiser.pdf], Erişim tarihi: 12 Mayıs 2017.

Swetz, F. \& Hartzler J. S. (1991). Mathematical modeling in the secondary school curriculum. Reston, Virginia: NCTM.

Sriraman, B. (2006). Conceptualizing the model-eliciting perspective of mathematical problem solving. In M. Bosch (Ed.), Proceedings of theFourth Congress of the European Society for Research in Mathematics Education(CERME 4) (pp. 1686-1695). SantFeliu de Guíxols, Spain: FUNDEMI IQS, Universitat RamonLlull. 
Swan, M., Turner, R., Yoon, C., \& Muller, E. (2007). The roles of modelling in learning mathematics. In W. Blum, P. L. Galbraith, H. W. Henn ve M. Niss (Eds.), Modelling and applications in mathematics education: The 14th ICMI Study (pp. 275-284). New York: Springer.

Şahin, N. ve \& Eraslan, A. (2016). Ortaokul öğrencilerin modelleme deneyimleri: Kağıttan uçak yapma yarışması problemi. Ĕgitim, Bilim ve Teknoloji Araştırmaları Dergisi, 1 (1), 34-44.

Şahin, N. ve Eraslan, A. (2017). Fourth-grade primary school students' thought processes and challenges encountered during the butter beans problem. Educational Sciences: Theory \& Practice, 17 (1), 105-127.

Şen, Ö. (2017). Matematik dersi ortaokul öğretim programlarının karşılaştırılması: 2009-2013-2017. Curr Res Educ, 3 (3), 116-128.

Taş, U. E., Arıcı, Ö., Ozarkan, H. B., \& Özgürlük, B. (2016). PISA 2015 Ulusal Raporu. Ankara: MEB.

Turner, R. (2007). Modelling and applications in PISA. In W. Blum, P. Galbraith, H.-W. Henn, \& M. Niss (Eds.), Modelling and Applications in Mathematics Education, The 14. ICMI Study (pp. 433440). New York: Springer.

Urhan, S. ve Dost, Ş. (2016). Matematiksel modelleme etkinliklerinin derslerde kullanımı: Öğretmen görüşleri. Elektronik Sosyal Bilimler Dergisi, 15 (59), 1279-1295.

Verschaffel, L., Greer, B., \& De Corte, E. (2002). Everyday knowledge and mathematical modeling of school word problems. In K. P. Gravemeijer, R. Lehrer,H. J. van Oers, \& L. Verschaffel (Eds.), Symbolizing, modeling and tool use in mathematics education (pp. 171-195). Dordrecht, The Netherlands: Kluwer Academic Publishers.

Yanık, H. B., Bağdat, O. \& Koparan, M. (2017). Ortaokul öğretmen adaylarının matematiksel modelleme problemlerine yönelik görüşlerinin incelenmesi. Eğitimde Nitel Araştırmalar Dergisi-Journal of Qualitative Research in Education, 5 (1), 80-101.

Yıldırım, A. ve Şimşek, H. (2008). Sosyal bilimlerde nitel araştırma yöntemleri. Ankara: Seçkin Yayıncilik.

Yıldırım, Z. ve Işık, A. (2014). Matematiksel modelleme etkinliklerinin 5.sınıf öğrencilerinin matematik dersindeki akademik başarılarına etkisi. Kastamonu Eğitim Dergisi, 23 (2), 581-600.

Yu, S. Y. \& Chang, C. K. (2011). What did taiwan mathematics teachers think of model- eliciting activities and modelling teaching?. In G. Kaiser, W. Blum, R. B. Ferri and G. Stillman (Eds.), Trends in teaching and learning of mathematical modelling: ICTMA 14 (pp. 147-156). Netherlands: Springer.

Zbiek, R. M. \& Conner, A. (2006). Beyond motivation: Exploring mathematical modeling as a context for deepening students' understandings of curricular mathematics. Educational Studies in Mathematics, 63, 89-112. 


\section{Extended Abstract}

Mathematical model shows the characteristics of a daily life situation through a mathematical form such as formula, equation, symbol, graphic, table and figure. Mathematical modeling; after the abstraction of real life problems, transfer to mathematics language, analysis, and a cyclical process in which the solution is evaluated. In revised Turkish mathematics curriculum, it appears that the emphasis on mathematical modeling ability. The prospect of achievements is great between achievements, content, educational situations, and assessment items in the mathematics curriculum. It is known that the researches examining the mathematics curriculum in terms of various skills have been limited. In addition, Turkey's success level is not at the desired level in the international assessment tests. The mathematics curriculum is updated according to the developing conditions, Falling levels in the Turkey's math achievement levels emerges as a significant problem. It is thought that the contents of the mathematics curriculum should be examined by considering different dimensions. Mathematical modeling is associated with both problem solving and mathematical literacy skills commonly used in international exams. Considering this feature of mathematical modeling, it is important to examine the mathematics curriculum in the context of using mathematical modeling. It is thought that this research will contribute to the program review studies and will fill a significant gap in the mathematics education literature. In this context, it was aimed to investigate mathematical models usage of mathematics curriculum (Middle Schools $5^{\text {th }}-8^{\text {th }}$ Grades) in this research. The document examined in the research is the mathematics curriculum published by Ministry of National Education. In the study, the data were analyzed descriptively. In the course of data analysis, explanations for the objectives and objectives in the program were examined in terms of mathematical model usage (MMU). According to results, it has been determined that MMU was most included in the eighth grade's objectives, while MMU was found to be at least in the sixth and seventh grade's objectives. In the findings, it was determined that the MMU took place in the fifth and seventh grades. It was also found that MMU was most involved in data processing learning area in fifth, seventh and eighth grade objectives. Moreover, in the sixth grade objectives of the MMU, it was determined that it took place mostly in the field of geometry and measurement learning area. According to grade levels, learning areas where MMU has the least involvement in objectives; geometry and measuring for fifth and seventh grades, algebra for sixth grade, probability for eighth grade. The results of the studies carried out on the explanations about the objectives show that the MMU is involved in numbers and transactions at the fifth and sixth grades; in the field of data processing learning at the seventh and eighth grade levels the mostly. In the explanations for objectives according to grade levels, MMU has the least learning areas such as; geometry and measurement for the fifth, sixth and seventh grades, probability for the eighth grade. Especially in the area of geometry, MMU is thought to be important for students to realize meaningful learning by abstracting geometric structures and concepts. However, in both the objectives and the explanations for the objectives, MMU has not been adequately addressed in the field of geometry. It is recommended that mathematical model and modeling expressions, examples of activities, explanations about modeling should be more space in mathematics curriculum objectives, which are a tool that determines the content of a mathematics course and guides teachers, In future research, detailed qualitative analysis can be done in terms of having mathematical modeling principles of problems in mathematics textbooks. In order to determine the international level of the program in Turkey, the programs of successful countries in exams such as TIMSS, PISA can be comparatively examined in the context of MMU. Also, it is suggested to conduct experimental researches to develop knowledge and skills for mathematical modeling and modeling and to examine the results for teachers who will implement modeling activities in class. 